\title{
Glutathione in induced sputum of healthy individuals and patients with asthma
}

\author{
N Dauletbaev, J Rickmann, K Viel, R Buhl, T-O-F Wagner, J Bargon
}

\begin{abstract}
Background-Glutathione is central to the antioxidant defences of the lung. The aim of this study was to determine whether sputum induction can be used for the measurement of glutathione in the respiratory tract.

Methods-Saliva and induced sputum (3\% $\mathrm{NaCl}, 20$ minutes) samples were collected from 10 healthy individuals and 10 patients with stable asthma receiving treatment with inhaled corticosteroids. Samples were chilled on ice and dispersed by dilution with ice cold phosphate buffered saline and pipetting. Cell-free supernatants were obtained by centrifugation of samples and filtration of supernatants and analysed for total glutathione, glutathione disulfide, and albumin content. The cells were treated with dithiothreitol and cell numbers, cell viability, and differential cell patterns were determined.
\end{abstract}

Results-As judged by cell viability and percentage of non-squamous cells, adequate sputum samples were obtained from nine healthy and nine asthmatic subjects. The salivary total glutathione content was low (median concentration $1.2 \mu M$ (range $0.8-1.5$ ) in healthy subjects and $0.9 \mu M(0.7-1.2)$ in asthmatic subjects). The sputum total glutathione content of both healthy and asthmatic subjects was within the same range (3.9 (1.0-12.3) $\mu M$ and $6.4(1.3-19.2) \mu M$, respectively; $p=0.35)$. Surprisingly, and in marked contrast to results obtained with bronchoalveolar lavage, sputum levels of glutathione disulfide represented more than $50 \%$ of the total glutathione in both groups $(50.9 \%$ (range 24.6-83.1) and $72.3 \%$ (range 36.5-97.4), respectively; $p=0.2$ ). Conclusions-The results of this study indicate that sputum induction can be used to measure the glutathione content of bronchial secretions. Sputum glutathione levels of stable asthmatic patients did not differ significantly from healthy controls. (Thorax 2001;56:13-18)

Keywords: glutathione; glutathione disulfide; induced sputum; asthma

Drentenary Medicine, Department of Internal Medicine II,

Frankfurt University

Hospital, Theodor-Stern-Kai

7, 60590 Frankfurt/Main,

Germany

bargon@t-online.de

Received 29 July 1999

Returned to authors

4 October 1999

Revised version received

20 September 2000

Accepted for publication

29 September 2000

The mammalian lung is exposed to oxidants inhaled with ambient air. ${ }^{12}$ Activated inflammatory cells are also an important source of free radicals in the lung. ${ }^{1}$ To scavenge these radical species, airway surfaces are covered with a thin liquid film (epithelial lining fluid) containing a number of antioxidants. One of these antioxidants is glutathione, a tripeptide containing an $\mathrm{SH}$ group. ${ }^{2-4}$ Its significance for antioxidant protection of the lung has been shown by numerous experiments in animals and investigations in humans. In humans the glutathione concentrations in the epithelial lining fluid are normally much higher than in blood. ${ }^{5}$ They have also been reported to be higher in the epithelial lining fluid of smokers and patients with chronic obstructive pulmonary disease (COPD) ${ }^{56}$ and to be markedly lower in the epithelial lining fluid of subjects with adult respiratory distress syndrome (ARDS), cystic fibrosis, and pulmonary fibrosis. ${ }^{7-9}$ Determination of the airway glutathione content is of use when investigating oxidative stress in the lung. To date, airway secretions have been collected during bronchoscopy to measure the glutathione content, although the sampling of bronchial secretions and cells by sputum induction was introduced some years ago. The aim of this study was to evaluate the feasibility of glutathione measurement in induced sputum from healthy individuals and patients with lung disease. We report the method of sputum processing and present the results of investigating the glutathione concentrations in induced sputum samples of healthy subjects and patients with asthma.

\section{Methods}

STUDY GROUPS

Ten healthy subjects and 10 patients with stable mild to moderate persistent allergic asthma participated in this study (table 1). The healthy subjects were non-smokers without any chronic lung disease or signs of acute respiratory infection during the preceding four weeks. Bronchial asthma was characterised by clinical symptoms (dyspnoea, cough, chest tightness) and a history of the disease (intermittent manifestations upon contact with allergen), and documented by measuring airway hyperreactivity and lung function parameters. ${ }^{10}$ The relevant allergens were determined by history and skin prick tests with common aeroallergens. All asthmatic patients received treatment with $400-800 \mu \mathrm{g}$ budesonide or $500 \mu \mathrm{g}$ fluticasone propionate per day and short acting inhaled $\beta$ agonists as required. The minimum time between the last medication and the visit to the clinic was four hours. None of the participants was receiving drugs such as $\mathrm{N}$-acetylcysteine which could affect bronchial glutathione levels.

All subjects gave informed consent to participate in the study and the study protocol was approved by the local ethics committee.

SPUTUM INDUCTION

Sputum inductions were performed between 10.00 and 14.00 hours. Before sputum induction lung function measurements were per- 
Table 1 Demographic and lung function data of healthy and asthmatic subjects

\begin{tabular}{lll}
\hline & $\begin{array}{l}\text { Healthy subjects } \\
(n=10)\end{array}$ & $\begin{array}{l}\text { Asthmatic patients } \\
(n=10)\end{array}$ \\
\hline Age (years) & $29(22-34)$ & $29(17-40)$ \\
$\mathrm{M} / \mathrm{F}$ & $9 / 1$ & $8 / 2$ \\
$\mathrm{FEV}_{1}(1)$ & $4.7(3.1-5.0)$ & $3.6(2.7-5.22)$ \\
$\mathrm{FEV}_{1}(\%$ pred) & $105.3(84.7-112.4)$ & $91.4(64.5-125.5)$ \\
$\Delta \mathrm{FEV}_{1}(\%) \dagger$ & $1.5(-3.2-5.2)$ & $1.5(-10.4-10.2)$ \\
\hline
\end{tabular}

Values are median (range).

$\mathrm{FEV}_{1}=$ forced expiratory volume in one second

†Change of $\mathrm{FEV}_{1}$ after sputum induction (\%).

formed. The safety of sputum induction was monitored by measuring peak expiratory flow rates (PEFR). The procedure would have been stopped if PEFR decreased by $25 \%$. After sputum induction the lung function measurements were repeated.

Sputum induction was performed by inhalation of $3 \% \mathrm{NaCl}$ for 20 minutes from an ultrasonic nebuliser (Ultra-Neb 2000, DeVilbiss 99; DeVilbiss Medizinische Produkte $\mathrm{GmbH}$, Langen, Germany) which generates particles of median diameter $4.5 \mu \mathrm{m}$ (nebulised output $2.4 \mathrm{ml} / \mathrm{min}$ ). The median output of the nebuliser for the whole study group was $38 \mathrm{ml}$.

Since saliva also contains glutathione, ${ }^{11}$ we determined whether salivary glutathione could alter measurement of the sputum glutathione content. Subjects rinsed their mouths with distilled water and collected $3-5 \mathrm{ml}$ saliva in plastic tubes. These samples were processed in parallel with and similar to sputum samples and analysed for glutathione content. Furthermore, since dilution of sputum samples by saliva may reduce the sputum content, ${ }^{12}$ subjects were instructed to discard excessive saliva into a separate vial during the sputum induction and to rinse their mouths with distilled water before each sputum expectoration. In addition, portions contaminated with saliva were removed from the sputum as described below.

To facilitate sputum production subjects were encouraged to expectorate the sputum at least five times during the induction procedure. Sputum was collected in sterile plastic tubes placed on ice to slow down metabolic processes which might result in loss of glutathione.

SAMPLE PROCESSING

Saliva and sputum samples were processed within 30 minutes of collection. Volumes were measured and portions with macroscopically visible salivary contamination were removed from the sputum. Samples were diluted with three volumes of chilled phosphate buffered saline (PBS; all reagents were purchased from Sigma-Aldrich Chemie $\mathrm{GmbH}$, Steinheim, Germany) and dispersed by gently agitating the tube and aspirating the sample with a wide bore pipette. Supernatants were obtained by centrifugation $\left(300 \mathrm{~g}, 15\right.$ minutes, $4^{\circ} \mathrm{C}$ ) and transferred to another vial by filtering through multiple layers of cotton gauze. Additional centrifugation $\left(800 \mathrm{~g}, 5\right.$ minutes, $\left.4^{\circ} \mathrm{C}\right)$ ensured removal of the remaining cell debris and mucus. Aliquots of the supernatants were placed on ice and assayed immediately for total glutathione and glutathione disulfide. The remaining supernatant was stored at $-80^{\circ} \mathrm{C}$ for determination of albumin.

The pellet was diluted with three volumes (per gram of pellet) of freshly prepared $6.5 \mathrm{mM}$ dithiothreitol (DTT) in PBS, vortexed, and incubated at $37^{\circ} \mathrm{C}$ for 15 minutes with occasional mixing. The cell suspension was dispersed, filtered through two layers of cotton gauze, and pelleted by centrifugation ( $300 \mathrm{~g}, 10$ minutes, $25^{\circ} \mathrm{C}$ ). The supernatants were discarded and the cells were resuspended in $2 \mathrm{ml} \mathrm{RPMI}$. Total and non-squamous cell numbers and total and non-squamous cell viability (Trypan blue exclusion) were determined. An aliquot of the cells containing 25 000-30 000 cells was cytospun at $57 g$ for 10 minutes at $25^{\circ} \mathrm{C}$ (Cytospin 2, Shandon, Frankfurt/Main, Germany). Cytospins were stained with May-Gruenwald-Giemsa dye and blindly analysed by two expert readers. At the first reading the percentage of squamous cells was determined and at the second reading (for sputum only) differential cell counts of nonsquamous cells (ciliated cells, macrophages, neutrophils, lymphocytes, eosinophils) were evaluated. At least 400 non-squamous cells were counted. Only sputum samples with nonsquamous cell viability of more than $60 \%$ and $60 \%$ or fewer squamous cells were analysed. For the saliva samples the validation criterion was based on cell viability only (viability $>60 \%$ ). Any samples of saliva or sputum contaminated with blood were excluded from analysis.

\section{GLUTATHIONE MEASUREMENT}

The total glutathione and glutathione disulfide content of saliva and induced sputum samples was measured using an enzymatic recycling assay. ${ }^{13} 14$ In this assay, reduced glutathione (GSH) reacts with 5,5'-dithio-bis-(2nitrobenzoic acid) (DTNB) to produce glutathione disulfide (GSSG) with stoichiometric formation of 5-thio-2-nitrobenzoic acid (TNB; absorbance maximum at $412 \mathrm{~nm}$ ). GSSG is reduced to GSH by the action of a highly specific glutathione reductase and $\beta$-nicotinamide adenine dinucleotide phosphate (NADPH). The rate of formation of TNB is proportional to the sum of GSH and GSSG present. The concentration of total glutathione (GSH + GSSG) in the sample was calculated by comparing its kinetic activity with that of serial GSSG dilutions in PBS (4-0.125 $\mu \mathrm{M}$ GSSG or 8-0.25 $\mu \mathrm{M}$ total glutathione) after subtracting the kinetic activity of the blank (PBS + reagents).

The standard and sample solutions were added to an equal volume of DTNB and $50 \mu \mathrm{l}$ of this mixture (final concentration of DTNB $0.25 \mathrm{mM}$ ) were pipetted into a $1 \mathrm{ml}$ cuvette followed by glutathione reductase and $\mathrm{NADPH}$ (final concentrations $1 \mathrm{U} / \mathrm{ml}$ and $0.22 \mu \mathrm{M}$, respectively). The reaction mixture was equilibrated and the kinetic reaction was followed for two minutes at $412 \mathrm{~nm}$ (spectrophotometer DU-70, Beckman Instruments $\mathrm{GmbH}$, Munich, Germany). All measurements were performed in duplicate. At this setting the 
Table 2 Saliva and sputum parameters in nine healthy and nine asthmatic subjects

\begin{tabular}{|c|c|c|c|}
\hline & $\begin{array}{l}\text { Healthy subjects } \\
(n=9)\end{array}$ & $\begin{array}{l}\text { Asthmatic patients } \\
(n=9)\end{array}$ & p value \\
\hline \multicolumn{4}{|l|}{ Saliva } \\
\hline Total cell number $\left(\times 10^{6}\right)$ & $0.5(0.2-1.1)$ & $0.7(0.3-1.9)$ & NS \\
\hline Squamous cells (\%) & $100(96-100)$ & $100(98-100)$ & NS \\
\hline Viability (total cells, \%) & $77(65-82)$ & $75(68-80)$ & NS \\
\hline Total glutathione $(\mu \mathrm{M})$ & $1.2(0.8-1.5)$ & $0.9(0.7-1.2)$ & NS \\
\hline Glutathione disulfide (\% of total) & $0.0(0.0-6.4)$ & $0.0(0.0-0.0)$ & NS \\
\hline Albumin $(\mu \mathrm{g} / \mathrm{ml})$ & $40(20-72)$ & $51(32-75)$ & NS \\
\hline \multicolumn{4}{|l|}{ Induced sputum } \\
\hline Volume $(\mathrm{ml})$ & $5.5(2.0-16.0)$ & $6.0(4.0-11.0)$ & NS \\
\hline Total non-squamous cell no $\left(\times 10^{6}\right)$ & $1.3(0.1-9.4)$ & $3.6(1.2-13.4)$ & $<0.02$ \\
\hline Viability (non-squamous cells, \%) & $87(75-98)$ & $89(70-92)$ & NS \\
\hline Squamous cells $(\%)$ & $18.0(5.0-58.0)$ & $19.0(2.0-38)$ & NS \\
\hline Macrophages (\%) & $63.0(25.0-94.0)$ & $69(47-96.0)$ & NS \\
\hline Neutrophils (\%) & $19.0(4.0-69.0)$ & $22.0(3.0-35.0)$ & NS \\
\hline Lymphocytes (\%) & $2.0(0.0-6.0)$ & $2.0(1.0-8.0)$ & NS \\
\hline Eosinophils (\%) & $0.0(0.0-2.0)$ & $0.0(0.0-11.0)$ & NS \\
\hline Ciliated cells (\%) & $3.5(1.0-24.0)$ & $2.0(0.0-9.0)$ & NS \\
\hline Total glutathione $(\mu \mathrm{M})$ & $3.9(1.0-12.3)$ & $6.4(1.3-19.2)$ & NS \\
\hline Glutathione disulfide (\% of total) & $50.9(24.6-83.1)$ & $72.3(36.5-97.4)$ & NS \\
\hline Albumin $(\mu \mathrm{g} / \mathrm{ml})$ & $52(42-82)$ & $124(76-171)$ & $<0.02$ \\
\hline
\end{tabular}

Data are represented as median (range) values.

Sputum samples with $>60 \%$ squamous cells were excluded from the analysis.

lower detection limit of the assay was $0.0625 \mu \mathrm{M}$ total glutathione.

The assay of total glutathione can be made specific for GSSG by masking any GSH present with $\mathrm{N}$-ethylmaleimide (NEM).$^{13} \mathrm{Sam}$ ples were mixed with an equal volume of $10 \mathrm{mM}$ NEM solution and excess NEM was removed by extraction through SEP-PAC $\mathrm{C}_{18}$ columns which were prepared by washing with methanol and distilled water. To $500 \mu \mathrm{l}$ of the eluate, DTNB (final concentration $0.2 \mathrm{mM}$ ), glutathione reductase (final concentration $2 \mathrm{U} /$ $\mathrm{ml}$ ), and NADPH (final concentration $0.25 \mathrm{mM}$ ) were added. After equilibration the kinetic reaction was followed spectrophotometrically as described above.

To ensure that the procedure did not result in a loss of glutathione, experiments with GSH/GSSG controls were performed. Known concentrations of GSH/GSSG were added to samples during various steps of sputum processing. Recovery of the control was expressed as a percentage of the expected value. In addition, we compared the recovery of glutathione controls from samples processed as described above and from samples treated with DTT.

\section{ALBUMIN MEASUREMENT}

The albumin content of the samples was measured using a modified method as previously described. ${ }^{15}$ In brief, a standard curve with a concentration range of $640-20 \mu \mathrm{g} / \mathrm{ml}$ was obtained by the dilution of purified human serum albumin in PBS. One $\mathrm{ml}$ of PBS (blank) or standard/sample was added to an equal amount of bromcresol green and the reaction was allowed to proceed for 10 minutes. The absorbance rates were measured spectrophotometrically at $628 \mathrm{~nm}$.

\section{ANALYSIS OF DATA}

Data are expressed as median (range). The Mann-Whitney U test was applied to compare the data. Relationships between variables were evaluated using the Spearman distribution free rank correlation test. A $p$ value of $\leqslant 0.05$ was considered statistically significant.

\section{Results}

SPUTUM INDUCTION

All subjects tolerated the sputum induction well. Only a small decrease in lung function parameters was observed during the procedure $(\mathrm{p}>0.5$; table 1$)$ and there were no further complications.

SALIVA AND SPUTUM CHARACTERISTICS

The saliva of all participants and sputum samples of nine healthy and nine asthmatic subjects were considered adequate. The sputum samples of the other two subjects had too many squamous cells $(>80 \%)$ and were excluded from analysis.

Healthy and asthmatic subjects did not differ significantly with respect to total cell counts, cell viability, and percentages of squamous cells in saliva ( $p>0.2$ all comparisons; table 2$)$. In contrast, some sputum parameters differed significantly between the two groupsspecifically, the sputum of asthmatic patients had significantly higher cell numbers $(\mathrm{p}<0.02$; table 2). No significant difference was observed in the differential cell counts between the two groups ( $p>0.15$ all comparisons; table 2$)$.

\section{GLUTATHIONE CONTENT OF SALIVA AND SPUTUM} SAMPLES

The total glutathione content of the saliva samples did not differ between healthy and asthmatic subjects $(p=0.4$; table 2$)$. Interestingly, glutathione disulfide was undetectable in all saliva samples (table 2 ). In both groups the glutathione content of the saliva was significantly lower than that of the sputum $(p<0.03$ both comparisons; table 2). Asthmatic patients tended to have higher glutathione concentrations in sputum samples (table 2) which were, however, not significantly different from those of healthy individuals $(p=0.35)$. Similarly, the absolute amounts and percentages of glutathione disulfide were not significantly different between the two groups, although they were slightly higher in the asthmatic group than in the healthy subjects $(72.3 \%$ (range 36.5-97.4) vs $50.9 \%$ (range $24.6-83.1$ ), $\mathrm{p}=0.2$; table 2 ). Interestingly, the total glutathione content correlated positively with the number of airway cells obtained in the induced sputum sample (fig 1). Furthermore, the glutathione content in the two sputum samples with high squamous

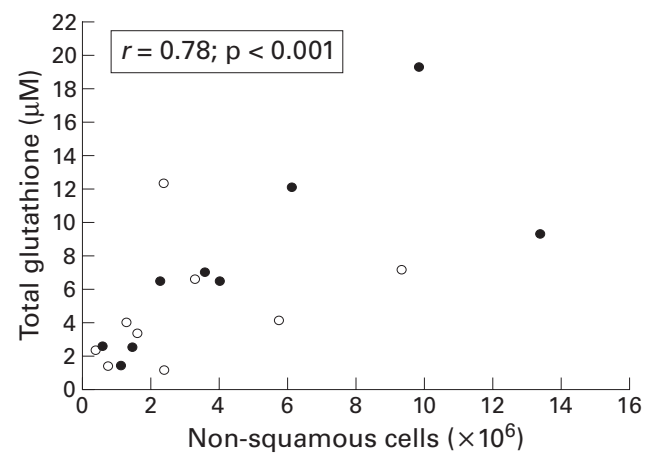

Figure 1 Relationship between total glutathione content $(\mu M)$ in the sputum and number of non-squamous cells $\left(\times 10^{6}\right)$. Open and closed symbols represent healthy $(n=9)$ and asthmatic $(n=9)$ subjects, respectively. 

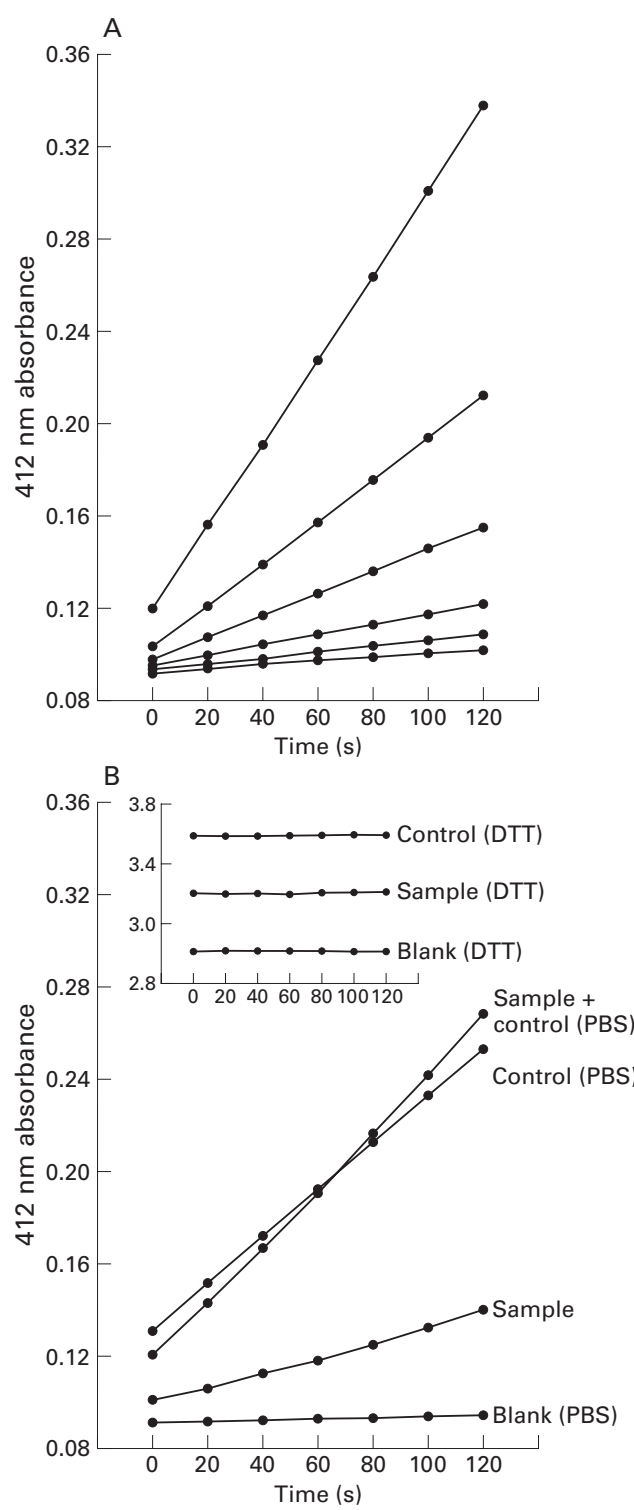

Figure 2 Kinetic activity of $(A)$ standards and $(B)$ blank, control, and sample. Note the different scale of the $y$ axis on the inset graph in (B). The glutathione concentration was calculated from the slopes of the standards in (A) (8-0.25 $\mu \mathrm{M}$ total glutathione). $G S H / G S S G$ control $(8 \mu M)$ was added to an equal volume of PBS (control (PBS)), sample (sample + control $(P B S)$ ), or $6.5 \mathrm{mM}$ dithiothreitol (DTT) (control (DTT)). The glutathione concentration measured in the control (PBS) sample corresponds to the expected value of $4 \mu M$. The recovery of GSH/GSSG control from sample + control (PBS) was $107 \%$. The presence of $6.5 \mathrm{mM} \mathrm{DTT}$ blocked the kinetic formation of 5-thio-2-nitrobenzoic acid which probably altered all the reactions used in the assay (see "Methods" section). The measurements were repeated in five sputum samples.

cell counts was very low and comparable to the glutathione level in the saliva (data excluded from analysis).

Experiments with GSH/GSSG controls showed complete recovery (median 105\%) of controls from the samples during the various steps of sample processing - for example, when added to the sample either before or after the first centrifugation (fig 2). Furthermore, our studies showed that the excess DTT significantly altered the kinetic reaction used in this assay.
ALBUMIN CONTENT OF SALIVA AND SPUTUM SAMPLES

There was no difference in the albumin content of saliva samples from healthy and asthmatic subjects $(p>0.2$; table 2$)$. In contrast, the albumin content of induced sputum samples of asthmatic patients was significantly higher than that of healthy subjects $(\mathrm{p}<0.02$; table 2$)$.

\section{Discussion}

This study was performed to evaluate the feasibility of using sputum induction to measure the glutathione content of airway secretions. Since glutathione disappears rapidly in biological samples as a result of auto-oxidation and transpeptidation processes, ${ }^{16}$ our study protocol was designed to minimise the metabolic loss of glutathione. In particular, saliva and sputum samples were processed using low temperatures and were assayed immediately. The latter point is of special importance since data from the literature ${ }^{7}$ and our own experience ${ }^{17}$ clearly show the rapid disappearance of glutathione in bronchoalveolar lavage fluid and sputum samples stored at $-80^{\circ} \mathrm{C}$.

The normal procedure of sputum processing was slightly modified in this study. Our samples were first diluted with PBS and dispersed by pipetting. Supernatants were then obtained by centrifugation of the samples. We omitted the use of DTT at this step because it is a potent reducing agent used to break crosslinking disulfide-glycoprotein bridges which maintain sputum in its gel form. ${ }^{18}$ This reagent is also used to release glutathione from glutathioneprotein mixed disulfides. ${ }^{19}{ }^{20}$ As we wished to evaluate the content of unbound glutathione present in bronchial secretions, we omitted the use of DTT while obtaining the sputum supernatant. In addition, under the experimental conditions used in this study, the excess DTT (6.5 $\mathrm{mM}$ initial concentration) significantly altered the kinetic reaction. We did not test whether other assay conditions would allow the use of DTT to obtain sputum supernatant. However, we believe that the use of PBS to disperse the sample did not result in a deterioration in the fluid phase outcome. In previous studies the use of PBS to homogenise sputum supernatant was satisfactory with respect to most fluid phase parameters. ${ }^{21}$ In agreement with these data, we observed high albumin concentrations in sputum supernatants of asthmatic patients. DTT was used in the latter stages of sample processing (to disperse the cell suspension) since its use results in significantly better cell recovery than the use of PBS alone. ${ }^{21}$

A very important finding of this study was the fact that the glutathione content of the saliva in both groups was significantly lower than that in the sputum. We conclude that glutathione in sputum samples represents exclusively the glutathione available in tracheobronchial secretions (with the exception of an insignificant contribution of salivary glutathione). Salivary glutathione in this study consisted almost entirely of the reduced form. This finding might be the result of a very low initial concentration of glutathione disulfide in the 
saliva which was reduced by subsequent dilution beyond the detection limit of the assay.

Our data indicate that the total glutathione content in these samples correlated with the airway cell count. There are several ways to interpret this finding. Firstly, the higher airway cell count might reflect the larger portions of bronchial secretions expectorated. Secondly, there may be a causal relationship between cell numbers and glutathione content. Although the origin of glutathione in the airways is still uncertain, lung cells and, in particular, macrophages are considered to be its major source. ${ }^{322}$ Thus, the greater the number of cells synthesising glutathione, the greater the glutathione content should be. In addition, glutathione might be passively released from cells by cellular breakdown. We believe, however, that the method of sputum processing used in the present study does not result in a significant leakage of glutathione from airway cells since the use of low temperatures has been found to prevent diffusion of glutathione out of the cells. ${ }^{23}$

We did not observe significant differences in total glutathione content between healthy and asthmatic subjects although there was a trend toward higher levels in patients with asthma. Indeed, the investigated population might have been too small to reveal a significant difference. We believe, however, that the use of antiinflammatory drugs by the patients with stable asthma may have influenced this sputum parameter. Like others, ${ }^{24}$ we were able to confirm the adequacy of the anti-asthmatic treatment by the prevalence of macrophages/ neutrophils in the induced sputum samples and the absence or low levels of eosinophils. The cellular characteristics of the sputum samples of healthy subjects were also similar to the published data - in particular, the median percentages of macrophages $(63.0 \%$ (range 25.0 $94.0)$ ) and neutrophils (19.0\% (range 4.0 69.0)) were comparable to those reported in the literature. ${ }^{25}$

The most striking finding of this study relates to the fraction of glutathione disulfide in the sputum samples. Previous studies of glutathione in the epithelial lining fluid of healthy subjects found the total glutathione to consist almost entirely of the reduced form..$^{5926}$ In contrast, in this study the total glutathione in both groups consisted of more than 50\% glutathione disulfide. It is unlikely that oxidation of the samples occurred during the processing procedure since we found high percentages of reduced glutathione in saliva which was processed in parallel with and in a similar way to the sputum. The discrepancy in the data on glutathione in bronchoalveolar lavage fluid is also unlikely to be caused by differences in methodology since we used the same kinetic assay. We consider that these findings reflect differences in glutathione levels in different lung compartments. Further studies of a direct comparison of induced sputum and epithelial lining fluid sampled during bronchoscopy are necessary to confirm this hypothesis.

No differences in the percentage of glutathione disulfide were found between healthy and asthmatic subjects, although there was a tendency towards higher levels in asthmatic patients. These data were obtained in stable patients receiving treatment with corticosteroids. It would be interesting to investigate the glutathione levels during an exacerbation and in steroid naive asthmatic patients.

In conclusion, the results of our study clearly show that sputum induction can be used to obtain bronchial secretions for the assessment of glutathione content. Oxidative stress is believed to contribute to the pathogenesis of a number of pulmonary diseases such as COPD and pulmonary fibrosis. Measurement of the sputum glutathione content may help to determine the localisation and extent of the oxidative processes within the respiratory tract in these diseases. Furthermore, such an investigation may be of assistance in assessing whether treatment with inhaled corticosteroids or $\mathrm{N}$-acetylcysteine could control the oxidative burden in the lung. The supernatant of induced sputum has recently been described as an "inexhaustible" source of information on events in the airways. ${ }^{12}$ We believe that our study further substantiates this concept.

This study was supported in part by Mukoviszidose e.V. Bonn.

1 Repine JE, Bast A, Landkhorst I, et al. Oxidative stress in chronic obstructive pulmonary disease. Am f Respir Crit Care Med 1997;156:341-57.

2 Rahman I, MacNee W. Lung glutathione and oxidative stress: implications in cigarette smoke-induced airway disstress: implications in cigarette smoke-1.

3 Cantin AM, Begin R. Glutathione and inflammatory disorders of the lung. Lung 1991;169:123-38.

ders of the lung. Lung 1991;169:123-38.
Repine JE, Heffner JE. Lung antioxidants. In: Crystal RG et al, eds. The lung: scientific foundations. Philadelphia, PA: Lippincott-Raven Publishers, 1997:2259-69.

5 Cantin AM, North SL, Habbard RC, et al. Normal alveolar epithelial lining fluid contains high levels of glutathione. $\mathcal{F}$ Appl Physiol 1987;63:152-7.

6 Melloni B, Lefebvre M-A, Bonnaud F, et al. Antioxidant activity in bronchoalveolar lavage fluid from patients with lung cancer. Am f Respir Crit Care Med 1996;154:1706-11.

Blvelar fluid in patients with the adult respiratory distress syndrome. Am Rev Respir Dis 1993;148:1174-8.

8 Cantin AM, Hubbard RC, Crystal RG. Glutathione deficiency in the epithelial lining fluid of the lower respiratory tract in idiopathic pulmonary fibrosis. Am Rev Respir tory tract in idiopath

9 Roum JH, Buhl R, McElvaney NG, et al. Systemic deficiency of glutathione in cystic fibrosis. I Appl Physiol 1993;75:2419-24.

10 National Heart, Lung, and Blood Institute. Guidelines for the diagnosis and management of asthma. NIH Publication No. 97-4051, 1997.

1 Tietze F. Enzymic method for quantitative determination of nanogram amounts of total and oxidized glutathione: application to mammalian blood and other tissues. Anal Biochem 1969;27:502-22.

12 Pavord ID, Pizzichini MM, Pizzichini E, et al. The use of induced sputum to investigate airway inflammation. Thorax 1997;52:498-501.

13 Akerboom TP, Sies H. Assay of glutathione, glutathione disulfide, and glutathione mixed disulfides in biological disulfide, and glutathione mixed disulfides

14 Buhl R, Vogelmeier C, Critenden M, et al. Augmentation of glutathione in the fluid lining the epithelium of the lower glutathione in the fluid lining the epithelium of the lower respiratory tract by directly administering glu
aerosol. Proc Natl Acad Sci USA 1990;87:4063-7.

15 Southcott AM, Jones KP, Li D, et al. Interleukin-8. Differential expression in lone fibrosing alveolitis and systemic sclerosis. Am f Respir Crit Care Med 1995;151: 1604-12.

16 Anderson ME. Determination of glutathione and glutathone disulfide in biological samples. Methods Enzymol 1985;113:548-55.

17 Viel K, Bargon J, Wiewrodt R, et al. Glutathione in bronchoalveolar lavage fluid and venous plasma before and after storage at $-80^{\circ}$ C. Eur Respir $\mathcal{F} 1995 ; 8$ (Suppl 19):596s.

18 Tockman MS, Qiao Y, Li L, et al. Safe separation of sputum cells from mucoid glycoprotein. Acta Cytol 1995;39:112836.

19 Paroni R, De Vecchi E, Cighetti G, et al. HPLC with o-phthalaldehyde precolumn derivatization to measure 
total, oxidized, and protein-bound glutathione in blood, plasma, and tissue. Clin Chem 1995;41:448-54.

20 Johannson M, Lenngren S. Determination of cysteine, glutathione and $\mathrm{N}$-acetylcysteine in plasma by ion-pai reversed-phase liquid chromatography and post-column derivatization. $f$ Chromatogr 1988;432:65-74.

21 Efthimiadis A, Pizzichini MM, Pizzichini E, et al. Induced sputum cell and fluid-phase indices of inflammation: comparison of treatment with dithiothreitol vs phosphatebuffered saline. Eur Respir F 1997;10:1336-40.

22 Heffner JE, Repine JE. Pulmonary strategies of antioxidant defense. Am Rev Respir Dis 1989;140:531-54.
23 Chieco P, Boor PJ. Use of low temperatures for glutathione histochemical stain. F Histochem Cytochem 1983;31:975-6.

24 Jatakanon A, Lim S, Barnes PJ. Changes of sputum eosinophils predict loss of asthma control. Am f Respir Crit Care Med 2000;161:64-72.

25 Belda J, Leigh R, Parameswaran K, et al. Induced sputum cell counts in healthy adults. Am F Respir Crit Care Med 2000;161:475-8.

26 van der Vliet A, O'Neill CA, Cross CE, et al. Determination of low-molecular-mass antioxidant concentrations in human respiratory tract lining fluids. Am $\mathcal{f}$ Physiol 1999;276:L289-96. 